\title{
Fluorescence Spectroscopic Studies of in vitro Interactions of Famotidine and Tapentadol Hydrochloride with Bovine Serum Albumin
}

\author{
Md. Rasal Hossain Khan ${ }^{1}$, Asma Rahman², Md. Zakir Sultan², Md. Zamil Sultan ${ }^{3}$ \\ and Mohammad A. Rashid ${ }^{1}$ \\ ${ }^{1}$ Department of Pharmaceutical Chemistry, Faculty of Pharmacy, University of Dhaka, Dhaka-1000, \\ Bangladesh \\ ${ }^{2}$ Centre for Advanced Research and Sciences (CARS), University of Dhaka, Dhaka-1000, Bangladesh \\ ${ }^{3}$ Department of Electrical and Electronic Engineering, Hajee Mohammad Danesh Science \\ and Technology University (HSTU), Dinajpur, Bangladesh
}

Received: January 01, 2016; Accepted: January 25, 2016; Published (web): February 11, 2016

\begin{abstract}
The in vitro interactions of Famotidine (FT) and Tapentadol hydrochloride (TAP) with bovine serum albumin (BSA) have been studied by fluorescence emission spectroscopy under different conditions. Quenching constants were determined using the Stern-Volmer equation. Two moles FT bound with 1 mole of BSA at $298 \mathrm{~K}$ and 3 mole FT bound with 1 mole of BSA at $308 \mathrm{~K}$ in presence of TAP. BSA was used for the study as it shows approximately $76 \%$ sequence homology to human serum albumin (HSA).
\end{abstract}

Key words: Famotidine, Tapentadol Hydrochloride, in vitro, bovine serum albumin, fluorescence, spectroscopy

\section{INTRODUCTION}

Serum albumin is the principal transporter of fatty acids that are otherwise insoluble in circulating plasma. The three dimensional structure of bovine serum albumin (BSA) and the crystal structure of human serum albumin (HSA) has $76 \%$ sequence homology. ${ }^{1}$ Famotidine (FT) is a histamine $\mathrm{H}_{2-}$ receptor antagonist. It is known to prevent NSAIDinduced UGI ulceration by reducing gastric acid secretion. FT inhibits $\mathrm{H}_{2}$ receptors, thus reducing basal, nocturnal, and stimulated gastric acid secretion. Through inhibition of $\mathrm{H}_{2}$ receptors present on parietal cells in the stomach FT prevents ulceration by reducing gastric acid secretion. $^{2}$ Tapentadol (TAP) is a centrally acting analgesic. It has an improved side effect profile when compared to

Correspondence to: Mohammad A. Rashid Tel.: 880-2-9661920, Ext. 8137; Fax: 880-2-9667222

E-mail: rashidma@du.ac.bd

Dhaka Univ. J. Pharm. Sci. 15(1): 21-26, 2016 (June) opioids and nonsteroidal anti-inflammatory drugs. Its dual mechanism of action makes it a useful analgesic to treat acute, chronic, and neuropathic pain. ${ }^{3}$ Frequently both of these drugs are used concomitantly. Therefore, it has a chance to interact with each other or influence the binding with serum protein by each other.

Spectral methods are powerful and effective tool for studying the reactivity of chemicals and biological systems because it allows nonintrusive measurements of substances in low concentration under physiological conditions. There are several studies of albumin induced by drugs or other bioactive small molecules using spectral methods. ${ }^{4-7}$ The fluorescence quenching data are usually analyzed by Stern-Volmer equation ${ }^{8}$ :

$$
\mathrm{F}_{\mathrm{o}} / \mathrm{F}=1+\mathrm{K}_{\mathrm{SV}}[\mathrm{Q}]
$$

Here, $F_{o}$ and $F$ are the fluorescence intensities in the absence and presence of quencher, respectively. The quencher concentration is $[\mathrm{Q}] . \mathrm{K}_{\mathrm{SV}}$ is the Stern- 
Volmer quenching constant, indicates the strength of interaction between the drug and BSA. It is the slope of the plot of $\mathrm{F}_{\mathrm{o}} / \mathrm{F}$ against concentration of drug based on the fluorescence data at different temperatures. $\mathrm{K}_{\mathrm{sv}}$ decreases with increasing temperature for static quenching while for dynamic quenching the reverse effect is observed. ${ }^{8}$ Thermodynamic parameters and nature of the binding forces:

$$
\ln \mathrm{K}_{\mathrm{a}}=-(\Delta \mathrm{H} / \mathrm{RT})+(\Delta \mathrm{S} / \mathrm{R})
$$

Here, $\Delta \mathrm{S}$ is the entropy change; constants $\mathrm{K}_{\mathrm{a}}$ are analogous to the Stern-Volmer quenching constants $\mathrm{K}_{\mathrm{SV}}$ at the corresponding temperature, $\mathrm{R}$ is the gas constant. The enthalpy $(\Delta \mathrm{H})$ and entropy $(\Delta \mathrm{S})$ changes can be determined from the slope and intercept of the fitted curve of $\ln _{\mathrm{SV}}$ against $1 / \mathrm{T}$, respectively. The free energy $(\Delta \mathrm{G})$ can be estimated from the following relationship:

$$
\Delta \mathrm{G}=\Delta \mathrm{H}-\mathrm{T} \Delta \mathrm{S}
$$

For reversible drug-protein binding, binding forces like hydrogen bonds, vander Waals forces, hydrophobic forces and electrostatic forces are involved.

Binding constant and binding points. When small molecule binds independently to a set of equivalent sites on a macromolecule, the equilibrium between free and bound molecule is given by the following equation:

$$
\log \left[\left(F_{o^{-}} F\right) / F\right]=\log K+\mathrm{n} \log [\mathrm{Q}]
$$

Where, $K$ and $\mathrm{n}$ are the binding constant to a site and the number of binding per albumin, respectively. The values of $K$ and $\mathrm{n}$ are calculated from the values of intercept and slope of the plot of $\log \left[\left(F_{o^{-}}-F\right) / F\right]$ versus $\log$ [drug], respectively.

In the present work, we studied the in vitro interactions between Famotidine (FT) and Tapentadol hydrochloride (TAP) with BSA by using fluorescence emission spectroscopy. ${ }^{9-11}$

\section{MATERIALS AND METHODS}

All chemicals and reagents were of analytical grade and double distilled water was used throughout the study. The solutions of drug and BSA were prepared in phosphate buffer of $\mathrm{pH} 7.4$ containing $0.01 \mathrm{M} \mathrm{Na} \mathrm{HPO}_{4}$ (Active Fine Chemicals Ltd., Bangladesh) and $0.02 \mathrm{M} \mathrm{KH}_{2} \mathrm{PO}_{4}$. Phosphate buffer of pH 7.4 was prepared. All fluorescence spectra were recorded on F-7000 spectrophotometer (Hitachi, Japan) equipped with $1.0 \mathrm{~cm}$ quartz cell. For different temperatures a thermostatic water bath (Unitronic Orbital, P Spectra, Spain) was used.

Sample preparation and spectroscopic measurement. Five $\mathrm{mL}$ of $20 \mu \mathrm{M}$ BSA solution, previously prepared in phosphate buffer of $\mathrm{pH} 7.4$ was taken in each of the eight test tubes. FT was added in different volumes to seven out of eight test tubes to have the following concentrations: 20 $\mu \mathrm{M}, 40 \mu \mathrm{M}, 80 \mu \mathrm{M}, 120 \mu \mathrm{M}, 160 \mu \mathrm{M}, 240 \mu \mathrm{M}$ and $320 \mu \mathrm{M}$. The ratio of FT and BSA was ([FT]/ [BSA] $=1,2,4,6,8,12,16)$ in the seven test tubes. The eighth test tube contained BSA solution only at $\mathrm{pH}$ 7.4. Phosphate buffer was marked as "control". BSA and the BSA-FT systems were stirred for $2 \mathrm{~min}$ and kept for $25 \mathrm{~min}$ at $298 \mathrm{~K}$ and $308 \mathrm{~K}$, respectively. In case of BSA-(FT+TAP), the concentration of TAP was remained constant. The parameters of the fluorescence spectrophotometer were set properly. Then estimation of the fluorescence intensity of the system at $298 \mathrm{~K}$ and $308 \mathrm{~K}$ and at the excitation wavelength of $280 \mathrm{~nm}$ and $293 \mathrm{~nm}$ were done, respectively. The width of both entrance and exit slit were set to $5 \mathrm{~nm}$. These emission spectra for all systems were recorded in the range of $320-460 \mathrm{~nm}$ for BSA at same experimental conditions.

\section{RESULTS AND DISCUSSION}

In order to determine whether both tryptophan and tyrosine residues of BSA are involved in interaction with FT, the fluorescence of BSA excited at $280 \mathrm{~nm}$ and $293 \mathrm{~nm}$ in the presence of FT were compared. When $280 \mathrm{~nm}$ excitation wave length was used, fluorescence of albumin comes from both 
tryptophan and tyrosine residues, whereas $293 \mathrm{~nm}$ wavelength only excites tryptophan-residues. ${ }^{12}$

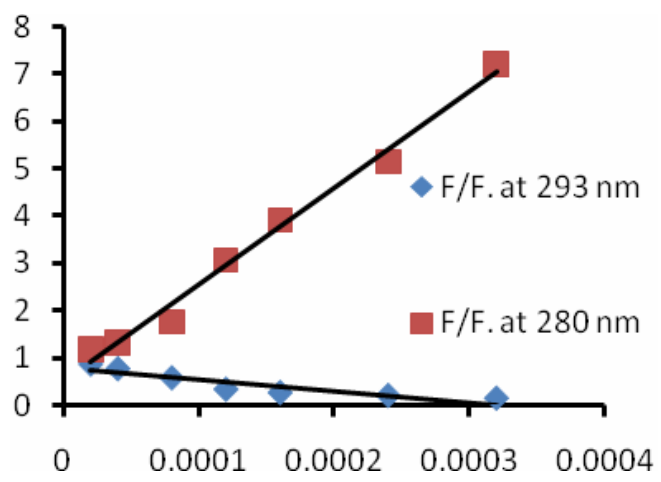

Figure 1. Fluorescence titration curve of BSA in the presence of FT at $\lambda_{\max }=280$ and $293 \mathrm{~nm}$.

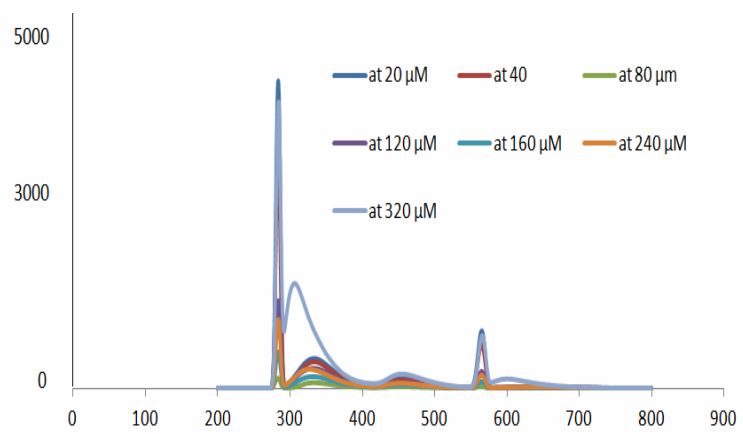

Figure 2. Fluorescence emission spectra of BSA in the presence of different concentration of FT $\left(\lambda_{\max }=280 \mathrm{~nm}, \mathrm{~T}=298 \mathrm{~K}\right)$.

The plots against [FT]/[BSA] (Figure 1) indicates that the fluorescence of BSA excited at 280 $\mathrm{nm}$ obviously differs from that excited at $293 \mathrm{~nm}$ in the presence of FT. This significant difference between quenching of serum albumin fluorescence shows that the both tyrosine and tryptophan residues participate in the molecular interactions between BSA and FT. Figure 2 shows the quenching of fluorescence of BSA. This indicates the strong interaction and energy transfer between FT and BSA. Fluorescence quenching is the decrease of the quantum yield of fluorescence from a fluorophore induced by a variety of molecular interaction with quencher molecule.

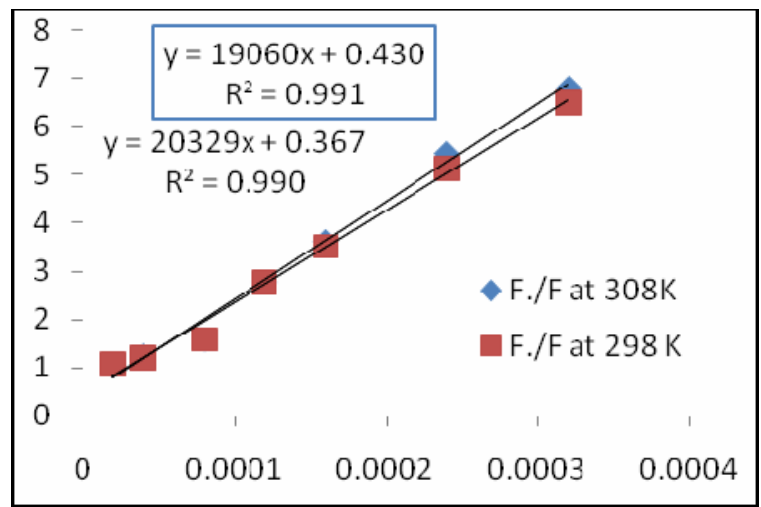

Figure 3. The Stern-Volmer plots for the quenching of BSA by FT at two different temperatures.

Table 1. Stern- Volmer quenching constant $\mathrm{K}_{\mathrm{sv}}$ of the system of FT- BSA $280 \mathrm{~nm}(\mathrm{R}=$ Correlation co-efficient).

\begin{tabular}{llll}
\hline $\mathrm{T}(\mathrm{K})$ & $1 / \mathrm{T}$ & $\begin{array}{l}\mathrm{K}_{\mathrm{sv}}\left(\mathrm{X} 10^{3} \mathrm{~L}\right. \\
\left.\mathrm{mol}^{-1}\right)\end{array}$ & $\ln \mathrm{S}_{\mathrm{sv}}$ \\
\hline 298 & 0.00336 & 19.06 & 9.8553 \\
308 & 0.00324 & 20.329 & 9.9198 \\
\hline
\end{tabular}

From table 1 it is clear that the probable quenching mechanism of the FT-BSA binding reaction is due to dynamic quenching.

The curves for the interactions of FT on the fluorescence emission spectra of BSA in presence of TAP showed in below:

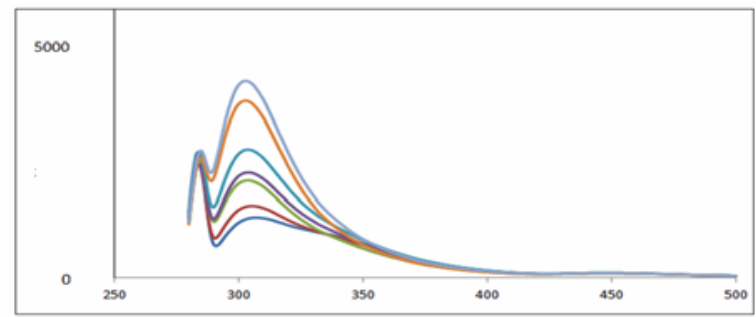

(a)

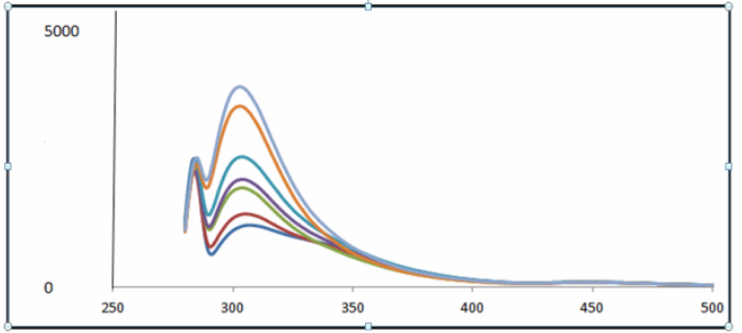

(b)

Figure 4. Fluorescence emission spectra of BSA-(FT+TAP) system at $280 \mathrm{~nm}$ at $298 \mathrm{~K}$ (a) and $308 \mathrm{~K}$ (b). 
Figure 4 shows the fluorescence emission spectra of BSA with varying concentrations of FT in presence of TAP at $280 \mathrm{~nm}$ at $298 \mathrm{~K}$ (Figure 4a) at $280 \mathrm{~nm}$ at $308 \mathrm{~K}$ (Figure 4b). It indicated that in presence of TAP there was a strong interaction and energy transfer between FT and BSA in both excitation wavelength $\left(\lambda \mathrm{Ex}_{\max }\right.$ of $\left.\mathrm{BSA}=280 \mathrm{~nm}\right)$ at two different temperatures. So it was found that the respective fluorescence intensity of BSA by increasing concentrations of FT in presence of TAP decreased in BSA-(FT+TAP) system.

Determination of $\mathbf{K}_{\mathrm{sv}}$ for BSA-(FT+TAP) system at $293 \mathrm{~nm}$. The following plots were drawn from the quenching of the interactions.

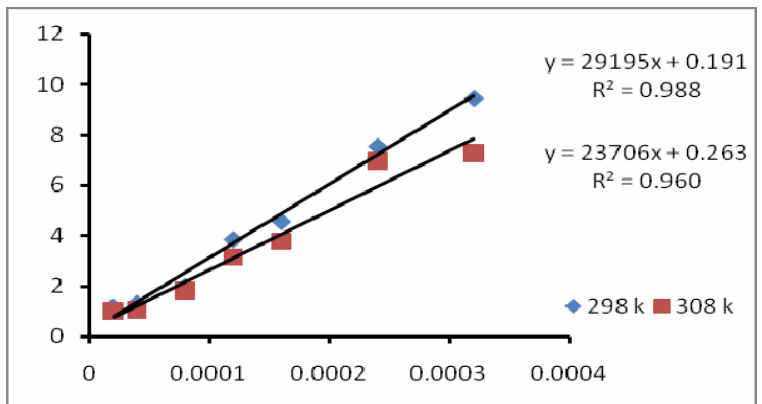

Figure 5. The Stern-Volmer plots for BSA-(FT+TAP) system at $293 \mathrm{~nm}$ at 298 and $308 \mathrm{~K}$.

Table 2. The Stern-Volmer quenching constant $\left(\mathrm{K}_{\mathrm{sv}}\right)$ for BSA(FT+TAP) system at $293 \mathrm{~nm}$ at two different temperatures.

\begin{tabular}{llll}
\hline $\mathrm{T}(\mathrm{K})$ & $1 / \mathrm{T}$ & $\mathrm{K}_{\mathrm{sv}}\left({\left.\mathrm{x} 10^{3} \mathrm{Lmol}^{-1}\right)}^{-1} \mathrm{nK}_{\mathrm{sv}}\right.$ \\
\hline 298 & 0.00336 & 29.195 & 10.28175 \\
308 & 0.00324 & 23.706 & 10.07348 \\
\hline
\end{tabular}

It is evident from table 2 that the probable quenching mechanism for the FT-BSA binding in presence of TAP at $293 \mathrm{~nm}$ was due to static quenching. It has been seen that Stern-Volmer constant increased in BSA-(FT+TAP) system than BSA-FT system at $293 \mathrm{~nm}$ at both temperatures. It indicated that the quenching of BSA by FT in BSA(FT+TAP) system was stronger than the quenching in BSA-FT system at $293 \mathrm{~nm}$ due to the presence of TAP. So, the quenching of BSA by FT was increased in BSA-(FT+TAP) system at $293 \mathrm{~nm}$ due to presence of TAP.

Table 3. Thermodynamic parameters for BSA-(FT+TAP) system at $293 \mathrm{~nm}$ at two different temperatures (298 and $308 \mathrm{~K})$.

\begin{tabular}{llll}
\hline $\mathrm{T}(\mathrm{K})$ & $\Delta \mathrm{H}(\mathrm{KJ} / \mathrm{mol})$ & $\Delta \mathrm{S}(\mathrm{J} / \mathrm{mol})$ & $\Delta \mathrm{G}(\mathrm{KJ} / \mathrm{mol})$ \\
\hline 298 & -15.8962 & 32.16 & -25.4799 \\
308 & -15.8962 & 32.16 & -25.8015 \\
\hline
\end{tabular}

Table 3 indicates that the presence hydrophobic interaction and the possibility of hydrogen bonding was observed. The binding process was spontaneous. It was observed that the value of $\Delta \mathrm{H}$ and $\Delta \mathrm{G}$ for BSA-(FT+TAP) system increased and value of $\Delta \mathrm{S}$ decreased at $293 \mathrm{~nm}$ at both temperatures than BSAFT system alone. It indicated that both stability and spontaneity of interaction of BSA with drugs in BSA(FT+TAP) system at $293 \mathrm{~nm}$ increased with decreasing randomness (entropy) due to presence of TAP.

Table 4. Binding constant and binding sites for BSA-(FT+TAP) system at $293 \mathrm{~nm}$ at two different temperatures.

\begin{tabular}{llll}
\hline $\mathrm{T}(\mathrm{K})$ & $\mathrm{K}($ Lmol-1) & $\log \mathrm{K}$ & $\mathrm{n}$ \\
\hline 298 & $1.444 \mathrm{X} 106$ & 6.1598 & 1.4839 \\
308 & $1.389 \mathrm{X} 1011$ & 11.143 & 2.8392 \\
\hline
\end{tabular}

Table 4 indicates that the binding constant increased with the increase in temperature of BSA(FT+TAP) system at $293 \mathrm{~nm}$ resulting in the increase of stability of the complex. The values of $n$ were found to be $\approx 2,3$ respectively at temperature $298 \mathrm{~K}$ and $308 \mathrm{~K}$. The molar ratio of the BSA-(FT+TAP) system at $293 \mathrm{~nm}$ was 1:2 and 1:3, respectively at temperature $298 \mathrm{~K}$ and $308 \mathrm{~K}$ indicated that 2 mole FT bound with 1 mole of BSA at $298 \mathrm{~K}$ and 3 mole FT bound with 1 mole of BSA at $308 \mathrm{~K}$ in presence of TAP. It was observed that the binding constant in BSA-(FT+TAP) system at $293 \mathrm{~nm}$ decreased (at 298 K) from BSA-FT system alone. It indicated that due to presence of TAP in BSA-(FT+TAP) system, the binding of BSA with drugs decreased at $293 \mathrm{~nm}$. The binding constant in BSA-(FT+TAP) system at 293 
$\mathrm{nm}$ increased (at $308 \mathrm{~K}$ ) from BSA-FT system alone. It indicated that due to presence of TAP in BSA(FT+TAP) system, the binding of BSA with drugs increased at $293 \mathrm{~nm}$.

Determination of $\mathrm{Ksv}$ for BSA-(FT+TAP) system at $280 \mathrm{~nm}$ : The Stern-Volmer constant (Ksv) for BSA-(FT+TAP) system at $280 \mathrm{~nm}$ at two different temperatures were calculated from the slope of the plot of $\mathrm{Fo} / \mathrm{F}$ versus concentration of FT in presence of TAP based on the fluorescence data at different temperatures.

Table 5. The Stern-Volmer quenching constant (Ksv) for BSA(FT+TAP) system at $280 \mathrm{~nm}$ at two different temperatures.

\begin{tabular}{llcl}
\hline $\mathrm{T}(\mathrm{K})$ & $1 / \mathrm{T}$ & $\mathrm{Ksv}\left(\mathrm{X} 10^{3} \mathrm{Lmol}-1\right)$ & $\operatorname{lnKsv}$ \\
\hline 298 & 0.00336 & 28.778 & 10.2674 \\
308 & 0.00324 & 28.263 & 10.2493 \\
\hline
\end{tabular}

From table 5 it is clear that the probable quenching mechanism was static. The quenching of BSA by FT was increased in BSA-(FT+TAP) system at $280 \mathrm{~nm}$ due to presence of TAP.

Thermodynamic parameters and nature of the binding forces for BSA-(FT+TAP) system at $280 \mathrm{~nm}$ at two different temperatures. The thermodynamic parameters and nature of the binding forces for BSA-(FT+TAP) system at $280 \mathrm{~nm}$ at two different temperatures are showed in the following table:

Table 6. Thermodynamic parameters for BSA-(FT+TAP) system at $280 \mathrm{~nm}$ at two different temperatures $(298 \mathrm{~K}$ and $308 \mathrm{~K})$.

\begin{tabular}{llll}
\hline $\mathrm{T}(\mathrm{K})$ & $\Delta \mathrm{H}(\mathrm{KJ} / \mathrm{mol})$ & $\Delta \mathrm{S}(\mathrm{J} / \mathrm{mol})$ & $\Delta \mathrm{G}(\mathrm{KJ} / \mathrm{mol})$ \\
\hline 298 & -19.07234 & 23.31 & -26.0187 \\
308 & -19.07234 & 23.31 & -26.2518 \\
\hline
\end{tabular}

Table 6 indicated that the hydrophobic interaction and hydrogen bonds were present. The binding process was spontaneous.
Table 7. Binding constant and binding sites for BSA-(FT+TAP) system at $280 \mathrm{~nm}$ at two different temperatures $(298 \mathrm{~K}$ and $308 \mathrm{~K})$.

\begin{tabular}{llll}
\hline $\mathrm{T}(\mathrm{K})$ & $\mathrm{K}($ Lmol-1) & $\log \mathrm{K}$ & $\mathrm{n}$ \\
\hline 298 & $1.2434 \mathrm{X} 106$ & 6.0946 & 1.4682 \\
308 & $2.7555 \mathrm{X} 106$ & 6.4402 & 1.5569 \\
\hline
\end{tabular}

From table 7 , the value of $\mathrm{n}$ was found to $\mathrm{be} \approx 2$ at both temperature $298 \mathrm{~K}$ and $308 \mathrm{~K}$. The molar ratio of the BSA-(FT+TAP) system at $280 \mathrm{~nm}$ was $1: 2$ at temperature $298 \mathrm{~K}$ and $308 \mathrm{~K}$ indicated that 2 mole FT bound with 1 mole of BSA at $298 \mathrm{~K}$ and $308 \mathrm{~K}$ in presence of TAP. It was observed that the binding constant in BSA-(FT+TAP) system at 280 $\mathrm{nm}$ increased (at $298 \mathrm{~K}$ and $308 \mathrm{~K}$ ) from BSA-FT system alone. It indicated that due to presence of TAP in BSA-(FT+TAP) system, the binding of BSA with drugs increased at $280 \mathrm{~nm}$.

\section{CONCLUSIONS}

Both tryptophan and tyrosine residues of BSA participated in the interactions with FT at the excitation wavelength of $280 \mathrm{~nm}$. FT-BSA binding reaction was due to dynamic quenching and this strong interaction was observed. The free energy change $(\Delta G)$ was negative, the enthalpy change $(\Delta H)$ was positive and the entropy $(\Delta S)$ was positive. Hydrophobic interaction was found, possibility of hydrogen bonding was rare and the binding process was spontaneous. The BSA-FT molar ratio of the system was 1: 2 at both $298 \mathrm{~K}$ and $308 \mathrm{~K}$. That means 1 mole of BSA bound with 2 mol of FT. In case of FT with BSA at $293 \mathrm{~nm}, \mathrm{FT}$ - BSA binding reaction was due to dynamic quenching. Strong interaction was observed. The free energy change $(\Delta G)$ and the enthalpy change $(\Delta H)$ were negative and the entropy $(\Delta S)$ was positive. Hydrophobic interaction was found, possibility of hydrogen bonding was found and the binding process was spontaneous. The BSA-FT molar ratio of the system was 1: 4 at both $298 \mathrm{~K} \& 308 \mathrm{~K}$. That means 1 mole of BSA bind with 4 mole of FT. In case of FT with BSA in the presence of TAP at $293 \mathrm{~nm}$, FT-BSA binding in presence of TAP at $293 \mathrm{~nm}$ was due to 
dynamic quenching. The free energy change $(\Delta \mathrm{G})$ and the enthalpy change $(\Delta \mathrm{H})$ were negative and the entropy $(\Delta \mathrm{S})$ was positive. Hydrophobic interaction was found, the possibility of hydrogen bonding was observed. The binding process was spontaneous. The stability and spontaneity of interaction of BSA with drugs in BSA-(FT+TAP) system at $293 \mathrm{~nm}$ increased with decreasing randomness (entropy) due to the presence of TAP.

The molar ratio of the BSA-(FT+TAP) system at $293 \mathrm{~nm}$ was $1: 2$ and 1:3, respectively at temperature $298 \mathrm{~K}$ and 308K. This indicated that 2 mole FT was bound with 1 mole of BSA at $298 \mathrm{~K}$ and 3 moles FT was bound with 1 mole of BSA at $308 \mathrm{~K}$ in presence of TAP. It was observed that the binding constant at $293 \mathrm{~nm}$ increased from BSA-FT system alone. It indicated that due to presence of TAP in BSA(FT+TAP) system, the binding of BSA with drugs increased at $293 \mathrm{~nm} .{ }^{13}$

\section{Competing interest}

Authors have declared no competing interest.

\section{REFERENCE}

1. Bill, X., Huang and Hee-Yong Kim, P.A. 2004. Probing three-dimensional structure of bovine serum albumin by chemical cross-linking and mass spectrometry. J. American Soci. Mass Spectro. 15, 1237-1247

2. Alfonso, E., Bello, M.D., MHS, FACP, FACR, DABPM, P.A. 2012. DUEXIS ${ }^{\circledR}$ (ibuprofen $800 \mathrm{mg}$, famotidine 26.6 $\mathrm{mg}$ ): a new approach to gastroprotection for patients with chronic pain and inflammation who require treatment with a nonsteroidal anti-inflammatory drug. Ther. Adv. Musculoskelet. Dis. 4, 327-339.
3. Singh, D.R., Nag, K., Akshaya, N., Shetti and Krishnaveni, N.P.A. 2013. Tapentadol hydrochloride: A novel analgesic. Saudi J. Anaesth. 7, 322-326.

4. Hua, C., Wu1, Y., Li1, Q., Zhang, B., Wang, W., Wang, Z. and Wenqing Gao, P.A. 2014. Spectroscopic investigation of the binding interactions of new berberine derivatives with bovine serum albumin. Int. J. Pharma. Toxi. 4, 155-161.

5. Zhang, H.X., Gao, S., Xiong, Z.Y. and Liu, S.P.P.A. 2009. Fluorometric probing on the binding of hematoxylin to serum albumin. Mol. Biol. Rep. 36, 2299-2306.

6. Zhang, H.X., Gao, S. and Yang, X.X.P.A. 2009. Synthesis of an octupolar compound and its biological effects on serum albumin. Mol. Biol. Rep. 36, 1405-1411.

7. Abuin, E., Calderon, C. and Lissi, E.P.A. 2008. Interaction of alkyl pyridinium chlorides with human serum albumin studied by fluorescence techniques. J. Photochem. Photobiol. A. 195, 295-300.

8. Lakowicz, J.R.P.A. 1999. Principles of Fluorescence Spectroscopy. 2nd Edition, Plenum Press, New York. http://dx.doi.org/10.1007/978-1-4757-3061-6

9. Sun, S.F., Zhou, B., Hou, H.N., Liu, Y. and Xiang, G.Y.P.A. 2006. Studies on the interaction between oxaprozin-E and bovine serum albumin by spectroscopic methods. Int. J. Biolo Macro. 39, 197-200.

10. Ross, P.D. and Subramanian, S.P.A. 1981. Thermodynamics of protein association reactions: forces contributing to stability. Biochem. 20, 3096-3102.

11. Li, D., Zhu, J., Jin, J. and Yao, X.P.A. 2007. Studies on the binding of nevadensin to human serum albumin by molecular spectroscopy and modeling. J. Mol. Struc. 846, 34-41.

12. Steinhardt, J., Krijn, J. and Leidy, J.G.P.A. 1971. Differences between bovine and human serum albumins: binding isotherms, optical rotatory dispersion, viscosity, hydrogen ion titration, and fluorescence effects. Biochem. 10, 4005-4015.

13. Rokonujjaman, M., Salam, M.A. and Sultan, M.Z.P.A. 2015. In vitro study of interactions of sildenafil citrate with bovine serum albumin in presence of bisoprolol fumarate and metformin hydrochloride by fluorescence spectrophotometry. British J. Med. Med. Res. 5, 362-375. 